\title{
Incidence and predictive factors of spinal cord stimulation treatment after lumbar spine surgery
}

\author{
This article was published in the following Dove Press journal: \\ Journal of Pain Research \\ 5 October 2017 \\ Number of times this article has been viewed
}

\author{
Merja Vakkala' \\ Voitto Järvimäki' \\ Hannu Kautiainen ${ }^{2,3}$ \\ Maija Haanpää4,5 \\ Seppo Alahuhta'
}

'Department of Anaesthesiology, Medical Research Center Oulu (MRC Oulu), Oulu University Hospital and University of Oulu, Oulu, ${ }^{2}$ Primary Health Care Unit, Kuopio University Hospital, Kuopio, ${ }^{3}$ Folkhälsan Research Center, Helsinki, ${ }^{4}$ Department of Neurosurgery, Helsinki University Hospital, ${ }^{5}$ Mutual Insurance Company Etera, Helsinki, Finland
Correspondence: Merja Vakkala Department of Anaesthesiology, Oulu University Hospital, PO Box 2I, 90029 Oulu University Hospital, Finland $\mathrm{Tel}+35883 \mathrm{I} 52 \mathrm{0l} \mathrm{I}$

Fax +35883156227

Email merja.vakkala@ppshp.fi
Introduction: Spinal cord stimulation (SCS) is recommended for the treatment of postsurgical chronic back and leg pain refractory to other treatments. We wanted to estimate the incidence and predictive factors of SCS treatment in our lumbar surgery cohort.

Patients and methods: Three questionnaires (a self-made questionnaire, the Oswestry Low Back Pain Disability Questionnaire, and the Beck Depression Inventory) were sent to patients aged 18-65 years with no contraindications for the use of SCS, and who had undergone nontraumatic lumbar spine surgery in the Oulu University Hospital between June 2005 and May 2008. Patients who had a daily pain intensity of $\geq 5 / 10$ with predominant radicular component were interviewed by telephone.

Results: After exclusions, 814 patients remained in this cohort. Of those, 21 patients had received SCS by the end of June 2015. Fifteen (71\%) of these received benefit and continued with the treatment. Complications were rare. The number of patients who replied to the postal survey were 537 (66\%). Eleven of them had undergone SCS treatment after their reply. Features predicting SCS implantation were daily or continuous pain, higher intensities of pain with predominant radicular pain, more severe pain-related functional disability, a higher prevalence of depressive symptoms, and reduced benefit from pain medication. The mean waiting time was 65 months (26-93 months). One hundred patients were interviewed by telephone. Fourteen seemed to be potential SCS candidates. From the eleven patients who underwent SCS after responding to the survey, two were classified as potential candidates in the phone interview, while nine were other patients. Twelve patients are still waiting for treatment to commence.

Conclusion: In our region, the SCS treatment is used only for very serious pain conditions. Waiting time is too long and it may be the reason why this treatment option is not offered to all candidates. Keywords: disc surgery, spinal fusion, decompression surgery, chronic back and leg pain, Beck Depression Inventory, Oswestry Disability Index

\section{Introduction}

Spinal cord stimulation (SCS) has been used for five decades to treat certain states of chronic pain refractory to other treatments. SCS is mainly used for chronic peripheral neuropathic pain (eg, radicular pain due to spine diseases or peripheral nerve trauma), but it has also been recommended for complex regional pain syndrome and certain types of ischemic vascular disease (refractory angina pectoris and severe peripheral limb ischemia). ${ }^{1,2}$ The most common condition for SCS is postsurgical chronic back and leg pain (CBLP), formerly called failed back surgery syndrome, referring to cases with continuing pain after adequate lumbar surgical procedure. ${ }^{3}$ For patients with CBLP, SCS has been reported to be superior to conservative medical management ${ }^{4}$ or reoperation ${ }^{5}$ in randomized studies. 
According to the International Neuromodulation Society, about 34,000 patients undergo spinal cord stimulator implants each year around the world. ${ }^{6} \mathrm{SCS}$ is shown to be cost-effective in the management of neuropathic or ischemic pain states. ${ }^{7}$

In SCS, an electrode is placed in the posterior epidural space at the level where electrical stimulation from the device produces a tingling sensation called paresthesia in the painful area and reduces pain by replacing the painful sensation. ${ }^{8}$ Test stimulations are administered over a period of few days using an external pulse generator to ensure sufficient response before implanting a permanent device under the skin. ${ }^{2}$

The mechanisms involved in pain-relieving effect of SCS are still not fully understood. According to the "gate control" theory, elective stimulation of the large-diameter afferent fibers $(A \beta)$ blocks the central transmission of small fibers $(\mathrm{A} \delta, \mathrm{C})$ and abolishes painful inputs. According to animal models, SCS seems to release many substances including substance P, glycin, gamma-aminobutyric acid, and serotonin, which are known to be involved with pain modulation in the spinal cord. It has been suggested that SCS may abolish peripheral ischemic pain by inhibiting sympathetic activity, reducing vasoconstriction, and releasing vasoactive agents from sensory fibers to cause vasodilatation. ${ }^{3}$

SCS is an invasive treatment which carries the risk of adverse events. Patients occasionally experience device complications, such as a displaced lead, an internally fractured electrode, or device malfunction. Major complications are, however, rare. ${ }^{9}$ The most common medical problems are bleeding at the implant site or infection. The latter usually necessitates removal of the device and antibiotic treatment. Persistent pain at the lead anchor site and implantable pulse generator pocket are important in $20 \%$ of patients, and up to $5 \%$ of patients require a pocket revision in order to achieve better comfort. ${ }^{6}$ According to a recent systematic review, adverse events in patients treated by SCS due to chronic low back pain conditions mostly included lead migration (13.2\%), lead breakage $(9.1 \%)$, and other minor hardware problems. The overall infection rate was $3.4 \% .^{10}$

We have previously reported the outcome of lumbar spine surgery in the Oulu University Hospital (OUH) based on a postal survey targeted at working-aged patients operated between 2005 and $2008 .{ }^{11-13}$ In this article, we have estimated the incidence of SCS in this cohort and sought factors predicting the use of SCS as a treatment option. We further evaluated a group of patients who predominantly had leg pain (ie, potential candidates for SCS) applying international criteria for SCS. ${ }^{14}$

\section{Patients and methods}

OUH is the main center of spinal surgery and the only one implanting SCS in Northern Finland. OUH provides specialist care for a population of 730,000. Lumbar spine surgery patients during the period June 1, 2005 to May 31, 2008 were identified using ICD-10 procedure codes. Acute traumas were excluded. Only working-aged patients (18-65 years) were included. Each patient was listed only once, and the index operation was defined as the latest lumbar spine surgery during the above mentioned period. Exclusion criteria were insufficient capacity in the Finnish language, major abuse problem, or progressive, severe illness (eg, cancer, dementia, organ failure). The ICD-10 diagnosis code for spinal disease and previous lumbar spine operations before the index surgery were recorded. The study protocol was approved by the Regional Ethics Committee of the Northern Ostrobothnia Hospital District, and the patients gave their written informed consent to participate in the study.

The questionnaires and a consent form were sent to all traceable patients in September 2009. The patients were asked to fill in three questionnaires: 1) a self-made questionnaire, 2) the Oswestry Low Back Pain Disability Questionnaire, and 3 ) the Beck Depression Inventory (BDI). The self-made questionnaire included questions regarding the occurrence of pain (never, occasionally, daily or almost daily, and all the time), the average intensity of pain (numeric rating scale [NRS], $0-10$ ), and pain-associated disability (NRS $0-10$ ). Axial low back pain and radicular pain were assessed separately. Self-reported weight and height were used to calculate body mass index. Relevant clinical data, including information on the trial and implantation of SCS, were updated from patient records until the end of June 2015.

Patients were selected through telephone interview as potential SCS candidates based on data from the self-made questionnaire. The patients interviewed by telephone were those who had daily pain intensity of $\geq 5 / 10$ and whose radicular pain component was more dominant than axial low back pain. Surgical, medical, and other treatments and their outcomes, general health condition, and working capacity were thoroughly discussed during the telephone interview. After this interview, the researcher (MV or VJ) judged whether the patient was a suitable candidate for SCS or not. Judgment criteria for SCS were daily pain intensity $\geq 5 / 10$ with a duration $\geq 6$ months despite appropriate noninvasive treatments, a dominant radicular pain component, no psychosocial contraindications for SCS (eg, abuse problems, major psychiatric disorders, low cognitive capacity, ongoing 
litigation process), no medical contraindications due to illnesses or their medication (eg, anticoagulants), no indications for new lumbar surgery, and the patient's own motivation for SCS treatment.

\section{Statistical analysis}

Descriptive statistics include means and SDs for continuous variables and numbers and percentages for categorical variables. Statistical comparison between the groups was performed by two-sample $t$-test or bootstrap type $t$-test, chisquare test, or Fisher-Freeman-Halton test when appropriate. The bootstrap method is significantly helpful when the theoretical distribution of the test statistic is unknown or in the case of a violation of the assumptions. The SCS incidence rates (per 1000 person-years) with 95\% CI were calculated assuming a Poisson distribution. Crude and standardized estimates of SCS incidence were calculated by using Poisson regression models. The normality of variables was evaluated by the Shapiro-Wilk $W$ test. Correlation coefficients were calculated by the Pearson method. All analyses were performed using STATA 14.1 (StataCorp LP, College Station, TX, USA). $P$-values $<0.05$ were considered significant.

\section{Results}

Figure 1 provides information on the study population. During the follow-up (from June 1, 2005 to June 30, 2015) 21 patients out of 809 had an SCS implanted. Those who underwent SCS implantation were compared to those who did not receive an SCS device. The demographic data and clinical characteristics of the patients are presented in Table 1. There were no significant differences between the groups.

In the entire lumbar spine surgery cohort (respondents and non-respondents, $n=809$ ), a total of 6741 person-years were followed up in 459 men and 350 women. During the follow-up (median 8.4 years [IQR 7.7-9.2]), 21 patients (3.0\% [95\% CI: 0.7-4.8]) underwent SCS implantation.

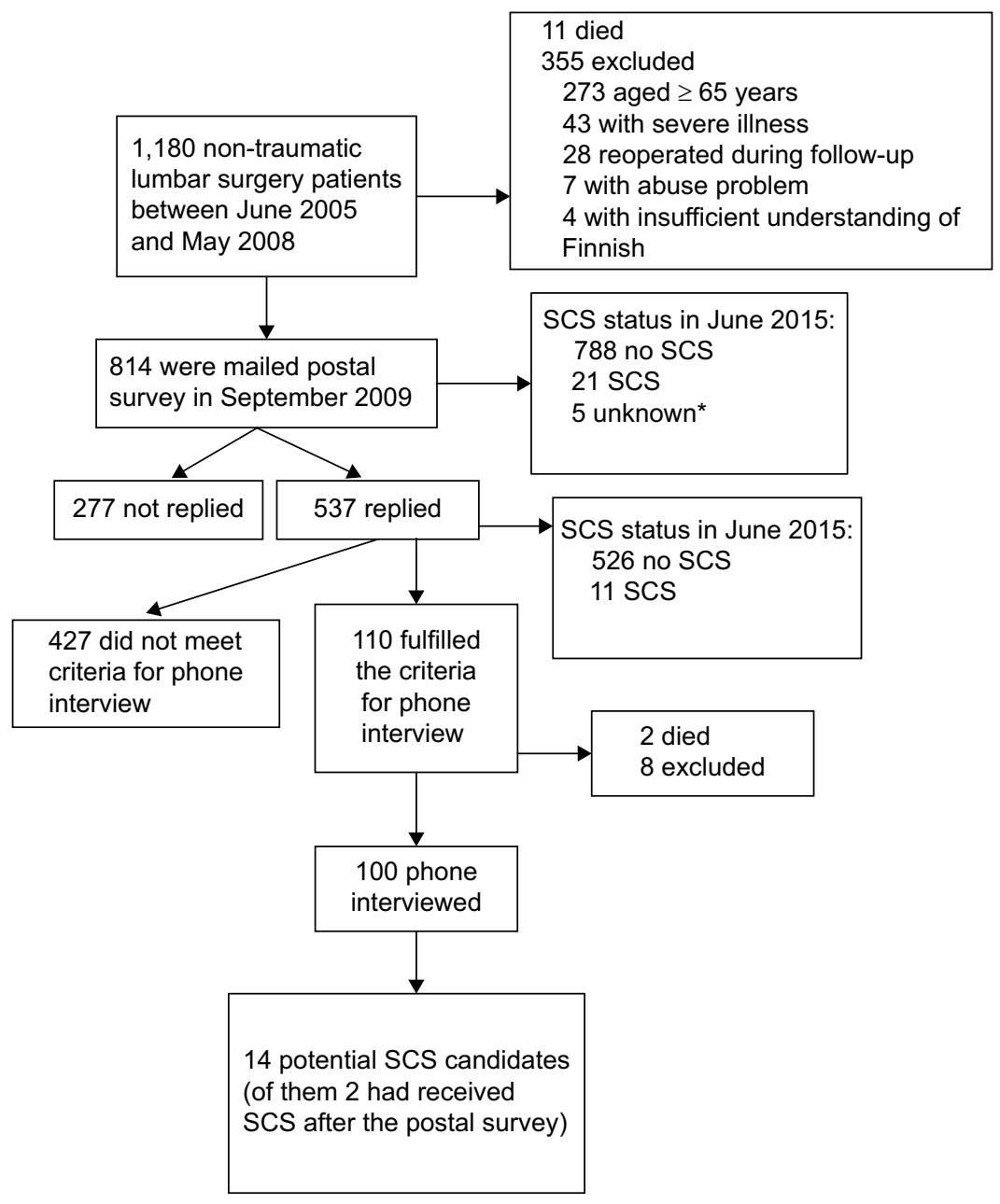

Figure I Flowchart of the lumbar surgery patients included in the study.

Note: *Not included in the analyses.

Abbreviation: SCS, spinal cord stimulation. 
Table I Demographic data

\begin{tabular}{|c|c|c|c|}
\hline & $\begin{array}{l}\text { Without SCS } \\
N=788\end{array}$ & $\begin{array}{l}\text { With SCS } \\
N=21\end{array}$ & $P$-value \\
\hline Number of female, $\mathrm{n}(\%)$ & $339(43)$ & II (52) & 0.39 \\
\hline Age, mean (SD) & $44(\mathrm{II})$ & $40(9)$ & 0.10 \\
\hline Diagnose, n (\%) & & & 0.080 \\
\hline M5I.Ia & $566(72)$ & $13(62)$ & \\
\hline M5I. $3^{\mathrm{b}}$ & $25(3)$ & $3(14)$ & \\
\hline M48.0 & $129(16)$ & $3(14)$ & \\
\hline$M 43 . I^{d}$ & $30(4)$ & $0(0)$ & \\
\hline M96 & $38(5)$ & $2(10)$ & \\
\hline Type of surgery, n (\%) & & & 0.34 \\
\hline Disc surgery & $549(69)$ & $12(57)$ & \\
\hline Stabilizing surgery & $124(16)$ & $4(19)$ & \\
\hline Decompression & $115(15)$ & $5(24)$ & \\
\hline
\end{tabular}

Notes: a Lumbar and other intervertebral disc disorders with radiculopathy, bother specified intervertebral disc degeneration, "spinal stenosis, dspondylolisthesis, epostsurgical musculoskeletal disorders without specific classification.

Abbreviation: SCS, spinal cord stimulation.

The total incidence of SCS was 3.12 per 1000 person-years (95\% CI: 2.03-4.78). The corresponding numbers for women and men were 3.75 (95\% CI: 2.08-6.78) and 2.62 (95\% CI: 1.41-4.88), respectively. The age- and diagnose-adjusted incidence rate was 1.33 (95\% CI: 0.55-3.22).

The success of SCS treatment was evaluated using patient records of these 21 SCS patients. Three stimulators were removed after the trial period and three shortly (2-8 months) after implantation. Fifteen out of 21 (71\%) patients received benefit from and continued to use the SCS. Eight patients have continued or returned to work, whereas seven have retired. Two patients were reported to gain excellent pain relief from the SCS and were able to discontinue all pain medication. Modifications in pain medication were not routinely documented. No hematomas or infections were reported. One patient suffered a post-spinal headache after implantation of the SCS and required a prolonged hospital stay. Five patients needed lead revisions, three of whom needed it twice. One SCS device was completely replaced. Two long-term stimulators were removed because of the need for MRI. Two patients died during the follow-up, the causes of death were without relation to SCS.

Altogether 537 patients responded to the postal survey, and 11 of them had an SCS implanted after the postal survey. Their results were compared to those respondents who did not receive an SCS (Table 2). Features of pain that predicted SCS implantation were daily or continuous pain, higher pain intensity (NRS) both in axial low back pain and radicular pain, and radicular pain intensity higher than axial low back pain. SCS patients had more pain-related disability according to both self-reported NRS and the Oswestry questionnaire. Their mean Oswestry Disability Index (ODI)
Table 2 Predictive factors for SCS implantation and comparison of respondents with or without SCS implanted during the followup period after the survey.

\begin{tabular}{|c|c|c|c|}
\hline & $\begin{array}{l}\text { Without } \\
\text { SCS } \\
N=526\end{array}$ & $\begin{array}{l}\text { With } \\
\text { SCS } \\
N=\text { I I }\end{array}$ & $P$-value \\
\hline Number of female, $n(\%)$ & $238(45)$ & $5(45)$ & 0.99 \\
\hline Age, mean (SD) & $45(11)$ & $43(8)$ & 0.39 \\
\hline Body Mass Index, mean (SD) & $27.3(4.8)$ & $28.9(6.1)$ & 0.31 \\
\hline Index operation first, n (\%) & $459(87)$ & $9(82)$ & 0.64 \\
\hline Type of surgery, n (\%) & & & 0.52 \\
\hline Disc surgery & $355(68)$ & $6(55)$ & \\
\hline Stabilizing surgery & $83(16)$ & $2(18)$ & \\
\hline Decompression & $87(17)$ & $3(27)$ & \\
\hline Occurrence of pain, n (\%) & & & $<0.001$ \\
\hline None & $40(8)$ & $0(0)$ & \\
\hline Occasionally & $191(37)$ & $0(0)$ & \\
\hline Daily & $243(47)$ & $4(36)$ & \\
\hline All the time & $46(9)$ & $7(64)$ & \\
\hline \multicolumn{4}{|l|}{ Pain intensity (NRS), mean (SD) } \\
\hline Axial low back pain & $4.2(2.3)$ & $5.8(2.3)$ & 0.031 \\
\hline Radicular pain & $3.7(2.7)$ & $6.3(1.6)$ & 0.002 \\
\hline Disability (NRS), mean (SD) & $4.9(2.7)$ & $7.4(1.6)$ & 0.003 \\
\hline Oswestry Disability Index, mean (SD) & $24(18)$ & $49(9)$ & $<0.001$ \\
\hline $\begin{array}{l}\text { Beck Depression Index Score, } \\
\text { mean (SD) }\end{array}$ & $9.2(8.7)$ & $22.1(10)$ & $<0.001$ \\
\hline Beck Depression Index Score $\geq 10$ & $201(38)$ & $10(91)$ & $<0.001$ \\
\hline $\begin{array}{l}\text { Response to pain medication, } \\
\text { (NRS 0-10), mean (SD) }\end{array}$ & $6.2(2.3)$ & $4.0(1.4)$ & 0.004 \\
\hline
\end{tabular}

Note: Two patients already had SCS at the time of the questionnaire and their results were excluded from this comparison.

Abbreviations: NRS, numeric rating scale; SCS, spinal cord stimulation.

value reflected severe functional disability compared to a moderate functional disability in those without SCS. Their mean Beck depression score was higher, reflecting moderate depression compared to normal values for those without SCS. According to the self-reported NRS, those with SCS received significantly less benefit from medication. The mean waiting time for SCS implantation was 65 months (26-93 months) from the index operation.

There were 110 respondents whose pain profiles fulfilled the criterion for phone interview. According to patient records, four of them were operated on after the index operation, two had passed away, and four already had an SCS when answering the survey. One hundred patients were interviewed.

After the thorough phone interview, 14 of the 100 patients appeared to be potential SCS candidates. Eleven patients received the SCS after they had responded to the survey. Two of these were classified as "potential SCS candidates" based on the phone interview and nine were other patients (Table 3). There was a strong positive correlation between BDI and ODI in the phone-interviewed group (Figure 2). 
Table 3 Number of potential SCS candidates according to the phone interview compared to number of implanted SCSs

\begin{tabular}{llll}
\hline SCS candidate & \multicolumn{3}{l}{ SCS implanted } \\
\cline { 2 - 4 } & No & Yes & Total \\
\hline No & 514 & 9 & 523 \\
Yes & 12 & 2 & 14 \\
Total & 526 & 11 & 537 \\
\hline
\end{tabular}

Abbreviation: SCS, spinal cord stimulation.

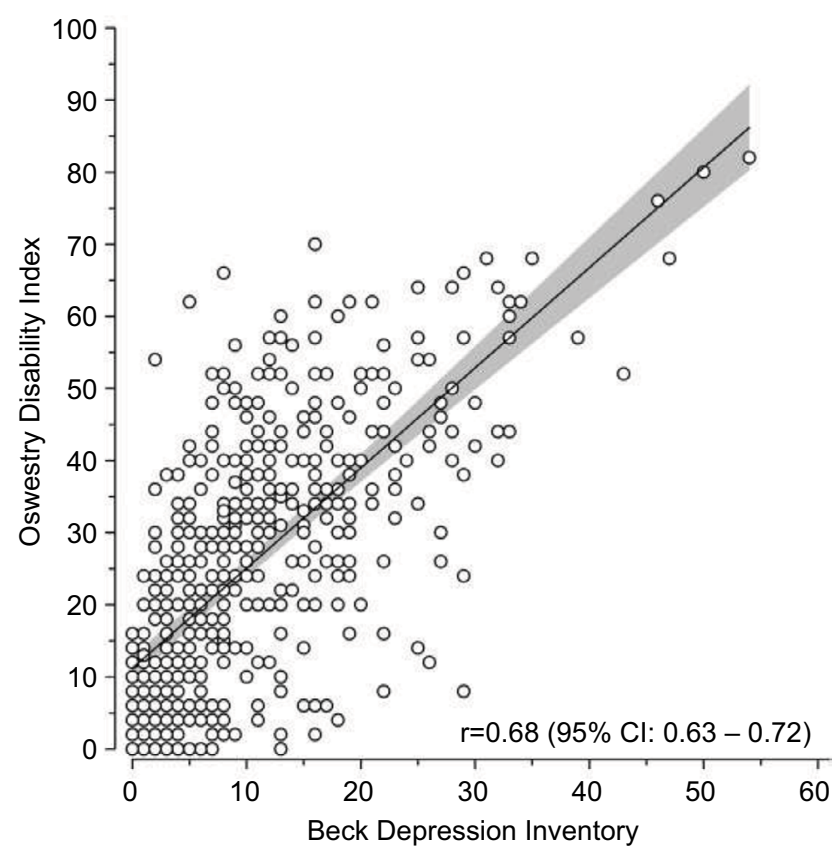

Figure 2 Relationship between $\mathrm{BDI}$ and $\mathrm{ODI}$ in the group interviewed by telephone. Note: Gray area represents $95 \%$ confidence intervals.

Abbreviations: BDI, Beck Depression Inventory; ODI, Oswestry Disability Index.

\section{Discussion}

The main findings of this study were a relatively low incidence of SCS for surgically operated CBLP patients, targeted to the most difficult pain conditions with a good outcome and few complications. Features of the pain that predicted SCS implantation were daily or continuous pain and higher intensities in both axial and radicular pain. SCS patients also had more severe levels of functional disability and more moderate depressive symptoms and benefited less from pain medication. According to our results, patient selection was compatible with international criterion, ${ }^{14}$ but patient selection was rather strict.

The mean waiting time for SCS in our hospital was 65 months, which is about the same as that reported in a retrospective analysis of $437 \mathrm{SCS}$ patients in Canada. ${ }^{15}$ The cumulative incidence of SCS was constant for up to 9 years. It has previously been confirmed that the long-term success rate of SCS is inversely proportional to the time interval between the beginning of the chronic pain syndrome and the implantation time. The efficacy of SCS exceeds $85 \%$ if implantation occurs within 2 years of symptom onset. ${ }^{16}$ Very few patients received SCS within 2 years of their index operation in our region.

It would appear that SCS as a treatment option does not cover all potential candidates in our region. Eleven respondents had SCS implanted during the follow-up time. Two of these had also been classified as potential candidates during the telephone interview. Nine patients who had SCS implanted were either non-respondents or did not otherwise fulfill our criteria for the telephone interview at the time of the survey. In addition, the telephone interview revealed 12 new potential candidates for trial. Our study was cross-sectional, and patients' pain status may have changed after they had answered the postal survey. It should also be kept in mind that final decision as to the applicability of an SCS trial period cannot be based on the telephone interview alone.

The study period of this report was 2005-2015. In 2008 the National Institute for Health and Care Excellence (NICE) published a technology appraisal guidance on SCS. This guidance recommends SCS as a cost-effective treatment for patients with neuropathic pain. ${ }^{17}$ In 2009, a systematic review on SCS came to a cautiously optimistic conclusion in our national Finnish Medical Journal: careful patient selection, avoidance of delays in treatment initiation, broad experience, and good expertise in both spinal nerve stimulation and other treatment options are important factors in obtaining the most effective treatment for neuropathic pain patients. ${ }^{18}$ Vyawahare et a ${ }^{19}$ assessed the impact of the NICE guidance by comparing SCS uptake in England pre-NICE and post-NICE. Despite the positive recommendation for the routine use of SCS, there was no increase in SCS uptake. ${ }^{19}$ This same tendency can be seen in our study: the incidence is constant throughout the years in this population, despite national and international recommendations.

It can be observed that the decision regarding the commencement of SCS treatment has been made without repeated operations, as there was no difference in re-operations between SCS patients and others. North et $\mathrm{al}^{5}$ compared SCS to repeated lumbosacral spine surgery in a prospective randomized controlled trial. They confirmed that SCS was more effective than reoperation as a treatment for persistent radicular pain after lumbosacral spine surgery. In the majority of cases it obviated the need for reoperation. ${ }^{5}$ 
SCS treatment is expensive, and in Finland, it is mainly offered to working-aged patients, which lead to age-limitation in our study. Of 15 long-term users, eight were able to return to work using SCS treatment along with other treatments. The role of SCS in the rehabilitation of these individuals cannot be ascertained from the results of this retrospective study alone. One could claim, however, that patient selection has been appropriate and that the cost-benefit analysis of these SCS treatments is positive in those cases. In health economics studies, the cost of an SCS system has been estimated to pay for itself within 3-4 years when compared to usual care. Patients who benefit have fewer medical visits, reduced pain medication use, improved quality of life, better sleep quality, greater activity levels, and may be more likely to return to work. ${ }^{6}$

This study examines the use of traditional SCS in lumbar surgery patients. The outcome of this treatment has been improved through continuous research and technological advancements in the field of neuromodulation. Traditional SCS (using a frequency range from 1 to $200 \mathrm{~Hz}$ ) requires that the paresthesia covers the area of pain to be effective. New techniques are showing promise in conditions that have not responded well to traditional SCS. High-frequency SCS involving stimulation rates of $10,000 \mathrm{~Hz}$ produces better pain relief without paresthesia. ${ }^{20}$ Dorsal root ganglion stimulation has been shown to be effective in conditions (such as CRPS) or locations (such as the inguinal region and foot) that have been challenging to treat with traditional SCS. ${ }^{21}$ New potential indications for stimulation are undergoing pilot studies, for example, in cluster headache or irritable bowel syndrome. ${ }^{22,23}$

There were several limitations in this study. Although the initial number of lumbar surgery patients was high, the number of SCS patients was low, and this somewhat impairs the comparison. The success of the SCS treatment was evaluated via patient records. Documentation was largely operation-orientated, and possible changes in pain profile, medication, functional disabilities, quality of life, and/or mood disturbances were not systematically documented.

\section{Conclusion}

It would appear that SCS treatment is used only for the treatment of very serious pain conditions in our region. This treatment option is not known well enough throughout the treatment pathway of the patients, and may possibly not be offered to all potential candidates. A regional strategy is necessary to reach these patients in time.

\section{Disclosure}

The authors report no conflicts of interest in this work.

\section{References}

1. Atkinson L, Sundaraj SR, Brooker C, et al. Recommendations for patient selection in spinal cord stimulation. J Clin Neurosci. 2011;18(10):1295-1302.

2. Song JJ, Popescu A, Bell RL. Present and potential use of spinal cord stimulation to control chronic pain. Pain Physician. 2014;17(3):235-246.

3. Epstein LJ, Palmieri M. Managing chronic pain with spinal cord stimulation. Mt Sinai J Med. 2012;79(1):123-132.

4. Kumar K, Taylor RS, Jacques L, et al. Spinal cord stimulation versus conventional medical management for neuropathic pain: a multicentre randomised controlled trial in patients with failed back surgery syndrome. Pain. 2007;132(1-2):179-188.

5. North RB, Kidd DH, Farrokhi F, Piantadosi SA. Spinal cord stimulation versus repeated lumbosacral spine surgery for chronic pain: a randomized, controlled trial. Neurosurgery. 2005;56(1):98-107.

6. Thomson S. Spinal cord stimulation role in managing chronic disease symptoms. International Neuromodulation Society; 2016. Available from: http://www.neuromodulation.com/spinal-cord-stimulation. Accessed August 31, 2017.

7. Kumar K, Rizvi S. Cost-effectiveness of spinal cord stimulation therapy in management of chronic pain. Pain Med. 2013;14(11):1631-1649.

8. Veizi E, Hayek S. Interventional therapies for chronic low back pain. Neuromodulation. 2014;17(Suppl 2):31-45.

9. Shamji MF, Westwick HJ, Heary RF. Complications related to the use of spinal cord stimulation for managing persistent postoperative neuropathic pain after lumbar spinal surgery. Neurosurg Focus. 2015;39(4):E15.

10. Cruccu G, Garcia-Larrea L, Hansson P, et al. EAN guidelines on central neurostimulation therapy in chronic pain conditions. Eur J Neurol. 2016;23(10):1489-1499.

11. Järvimäki V, Juurikka L, Vakkala M, Kautiainen H, Haanpää M. Results of lumbar spine surgery: a postal survey. Scand J Pain. 2015;6:9-13.

12. Järvimäki V, Kautiainen $H$, Haanpää $M$, et al. Depressive symptoms are associated with poor outcome for lumbar spine surgery. Scand J Pain. 2016;12:13-17.

13. Järvimäki V, Kautiainen H, Haanpää M, Alahuhta S, Vakkala M. Obesity has an impact on outcome in lumbar disc surgery. Scand J Pain. 2016;10:85-89.

14. Gybels J, Erdine S, Maeyaert J, et al. Neuromodulation of pain. A consensus statement prepared in Brussels 16-18 January 1998 by the following task force of the European Federation of IASP Chapters (EFIC). Eur J Pain. 1998;2(3):203-209.

15. Kumar K, Rizvi S, Nguyen R, Abbas M, Bishop S, Murthy V. Impact of wait times on spinal cord stimulation therapy outcomes. Pain Pract. 2014;14(8):709-720.

16. Kumar K, Wilson JR. Factors affecting spinal cord stimulation outcome in chronic benign pain with suggestions to improve success rate. Acta Neurochir Suppl. 2007;97(Pt 1):91-99.

17. NICE: Spinal cord stimulation for chronic pain of neuropathic or ischaemic origin. National Institute for Health and Care Excellence; 2008. Available from: http://www.nice.org.uk/guidance/ta159. Accessed October 22, 2008

18. Paavola $M$, Haanpää $M$, Kärkkäinen $M$, Pälvimäki E, Blom M, Malmivaara A. Spinal nerve stimulation in severe neuropathic pain and complex regional pain syndrome. A systematic review. Finn Med J. 2009;64(13):1241-1249.

19. Vyawahare B, Hallas N, Brookes M, Taylor RS, Eldabe S. Impact of the National Institute for Health and Care Excellence (NICE) guidance on medical technology uptake: analysis of the uptake of spinal cord stimulation in England 2008-2012. BMJ Open. 2014;4(1): e004182-2013-004182. 
20. Slavin KV. Spinal stimulation for pain: Future applications. Neurotherapeutics. 2014;11:535-542.

21. Deer TR, Levy RM, Kramer J, et al. Dorsal root ganglion stimulation yielded higher treatment success rate for complex regional pain syndrome and causalgia at 3 and 12 months: a randomized comparative trial. Pain. 2017;158(4):669-681.
22. Wolter T, Kiemen A, Kaube H. High cervical cord stimulation for chronic cluster headache. Cephalalgia. 2011;31(11):1170-1180.

23. Lind G, Winter J, Linderoth B, Hellstrom PM. Therapeutic value of spinal cord stimulation in irritable bowel syndrome: a randomized crossover pilot study. Am J Physiol Regul Integr Comp Physiol. 2015;308(10):R887-R894.

\section{Publish your work in this journal}

The Journal of Pain Research is an international, peer reviewed, open access, online journal that welcomes laboratory and clinical findings in the fields of pain research and the prevention and management of pain. Original research, reviews, symposium reports, hypothesis formation and commentaries are all considered for publication

\section{Dovepress}

The manuscript management system is completely online and includes a very quick and fair peer-review system, which is all easy to use. Visit http://www.dovepress.com/testimonials.php to read real quotes from published authors.

Submit your manuscript here: https://www.dovepress.com/journal-of-pain-research-journal 